\title{
Effects of TIG Reheating on Duplex Stainless Steel Weld Microstructure
}

\author{
B. VARBAI ${ }^{1 *}$, F. TOLnAI ${ }^{1}$, K. MÁJLINGER ${ }^{1}$ \\ ${ }^{1}$ Budapest University of Technology and Economics, Department of Materials Science and Engineering, \\ *varbai@eik.bme.hu
}

Abstract. Duplex stainless steels (DSS) gaining their excellent mechanical properties and corrosion resistance due to their austenitic-ferritic microstructure, ideally in the same amount. However, to keep this ideal phase ratio during arc welding is very difficult. Generally, the arc welding processes will result in more ferritic microstructure in the weld metal and in the heat affected zone, due to the rapid cooling. The ferritic microstructure can cause chromiumnitride precipitation, because the nitrogen solubility in ferrite phase is very low below $700{ }^{\circ} \mathrm{C}$. These chromiumnitride precipitations can cause loss of corrosion resistance and mechanical properties. However, during subsequent reheating, the chromium-nitrides can dissolve and act as a secondary austenite nucleation site in the ferritic microstructure.

In our research we welded DSS specimen autogenously, with tungsten inert gas welding using pure argon and $94 \%$ argon $+6 \%$ nitrogen as shielding gasses. In the first case the sub-sequent solid-state reheating caused $20 \%$ increase in the austenite fraction of the weld metal but with the use of mixed shielding gas only $5 \%$ increase.

\section{Introduction}

Among high strength structural steels the duplex stainless steels (DSSs) gaining more attention recently [1-9]. DSSs gaining their excellent mechanical properties and corrosion resistance due to their two-phase austenite-ferrite microstructure [10-11]. The ideal 1:1 phase ratio of the austenite/ferrite phases can easily be shifted in either more austenitic or ferritic as a result of welding processes [12-14]. In case of the weld metal (WM) and/or the heat affected zone (HAZ) microstructure is significantly austenitic or ferritic, the corrosion resistance and the mechanical properties can deteriorate. The highly ferritic microstructure can cause decrease in the mechanical properties such as ductility [15-17], and the highly austenitic microstructure can cause loss of corrosion resistance against chloride rich environments [18-19], such as sea water desalination plants, where most of the DSSs are being used [20-21]. Generally, the arc welding processes, such as tungsten inert gas (TIG) welding will result in more ferritic microstructure in the WM and the HAZ [22-23]. The reason for this is the relatively high cooling rate. All of the DSSs solidify as pure deltaferrite and the ferrite-to-austenite transformation happens during the solid-state cooling. This transformation is driven by atomic nitrogen diffusion in the microstructure [24]. The high cooling rate will allow less time for this diffusion, resulting in significantly ferritic microstructure in the WM and HAZ. In order to keep the ideal 1:1 phase ratio, nitrogen addition to the shielding gas is used in industrial applications in case of TIG welding of DSS [25-27]. The nitrogen addition to the shielding 
gas will result in more austenite formation in the WM and in the HAZ as nitrogen is 30 times more potent austenite former, than for example nickel [10]. On the other hand, the subsequent thermal cycle on the WM and HAZ (modelling multi-pass welds) will also result in more austenitic weld metal [2833]. The reason for this, is the longer available diffusion time for nitrogen atoms, which ensures the austenite formation in the microstructure.

In our paper we investigated the austenite/ferrite phase ratio in the WM of DSS TIG welding. First, we investigated the effects of $6 \%$ nitrogen addition to the shielding gas. Secondly, after the single-pass bead on plate welding, the multi-pass welding was modelled by subsequent solid state TIG reheating of the welds.

\section{Materials and methods}

\subsection{The used base material}

The used base material (BM) for the TIG welding and reheating was standard X2CrNiMoN22-5-3 (DSS 2205) duplex stainless steel in $6 \mathrm{~mm}$ thick sheet form. The chemical composition can be found in Table 1.

\begin{tabular}{ccccccccc}
\hline \multicolumn{3}{c}{ Chemical composition from the manufacturers data sheet (wt.\%) } \\
Cr & $\mathbf{N i}$ & $\mathbf{M n}$ & $\mathbf{M o}$ & $\mathbf{N}$ & $\mathbf{C}$ & $\mathbf{S i}$ & $\mathbf{C u}$ & $\mathbf{F e}$ \\
\hline 22.21 & 5.76 & 1.36 & 3.14 & 0.164 & 0.020 & 0.38 & 0.30 & bal. \\
\hline
\end{tabular}

Table 1. Chemical composition of the DSS 2205 BM in as-received condition.

The initial nitrogen $(\mathrm{N})$ content in the BM was measured by HORIBA EMGA 620-W analyser. The 0.164 wt.\% nitrogen content drives the ferrite-to-austenite transformation during solid-state cooling after welding.

\subsection{TIG welding and reheating processes}

The single pass bead-on-plate TIG welding was performed on $200 \times 50 \times 6 \mathrm{~mm}$ specimens, in PA position on a self-built Arc Specialties ${ }^{\circledR}$ equipment. This automatic arc voltage control ensures the constant $\operatorname{arc}$ energy (which is calculated as the heat input, taking the thermal efficiency as 1.0) during welding with different shielding gases. The used arc energy was constant $0.84 \mathrm{~kJ} / \mathrm{mm}$ in case of both of the shielding gases: pure argon (Ar) and $94 \% \mathrm{Ar}+6 \%$ nitrogen $\left(\mathrm{N}_{2}\right)$. The applied arc energy falls into the industrially advised $0.5-2.5 \mathrm{~kJ} / \mathrm{mm}$ range [1]. The subsequent TIG reheating was performed on the bead-on-plate welds in PA position, using Ar shielding gas, and very low, $0.183 \mathrm{~kJ} / \mathrm{mm}$ arc energy with direct current, sample positive polarity (DC-). This low arc energy ensured that, the specimens were staying in solid-state during the whole reheating process. The welds were reheating one time, along the whole length (modelling multi-pass welding). In both cases of the TIG welding and TIG reheating, the used tungsten electrode was $2 \%$ thoriated in $3.2 \mathrm{~mm}$ diameter and ground to a $40^{\circ}$ electrode angle. The arc length was kept at constant $2 \mathrm{~mm}$. The shielding gas flow rate was $10 \mathrm{l} / \mathrm{min}$ in all cases. 


\subsection{Evaluation methods}

\subsubsection{Cooling rate measurements}

The TIG welding process was recorded using FLIR ${ }^{\circledR}$ type thermal camera. The emissivity value was validated by K-type thermocouple temperature measurements (e.g. Figure 1.). The recorded videos of the TIG welding process can be evaluated, using the manufacturers software. In the software the measurement points can be placed anywhere freely and the temperature gradients can be obtained in a datasheet.

\subsubsection{Metallography and microstructure examination}

Standard metallography specimens were cut with diamond saw and constant cooling, from the cross section of the weldments, using constant cooling during the cutting process. The specimens were ground to 4000 grit sand paper and polished with $3 \mu \mathrm{m}$ diamond suspension. After polishing the specimens were etched using double etching method and Berahas reagent, as described in our previous work [34]. The optimal etching method ensures high contrast between ferrite and austenite phases. On the images ferrite grains appear dark and austenite grains remain light (e.g. Figure 3.). For the detection of possible nitride precipitations electrochemical etching was done according to ISO 17781:2017. The welded specimens were etched in $15 \%$ oxalic-acid solution, using $10 \mathrm{~V}$ direct potential for 10 seconds. The metallographic images were taken using Olympus PMG3 optical microscope. The phase ratio was measured by Fischer type Feritscope ${ }^{\circledR}$ FMP30.

\section{Results and discussion}

\subsection{Cooling rate results during TIG welding}

The $1200{ }^{\circ} \mathrm{C}$ to $800{ }^{\circ} \mathrm{C}\left(\mathrm{dT}_{12 / 8}\right)$ cooling rate is chosen for evaluation because, the cooling time in this temperature range is found to have the most effect on the ferrite-to-austenite phase transformation and thus the phase ratio [35-36]. An example image for the video recorded by the thermal camera can be seen in Figure 1., where the Sp are the measurement points. Sp1 point is placed in order to validate the temperature readings of the thermal camera by K-type thermocouples during the TIG welding.

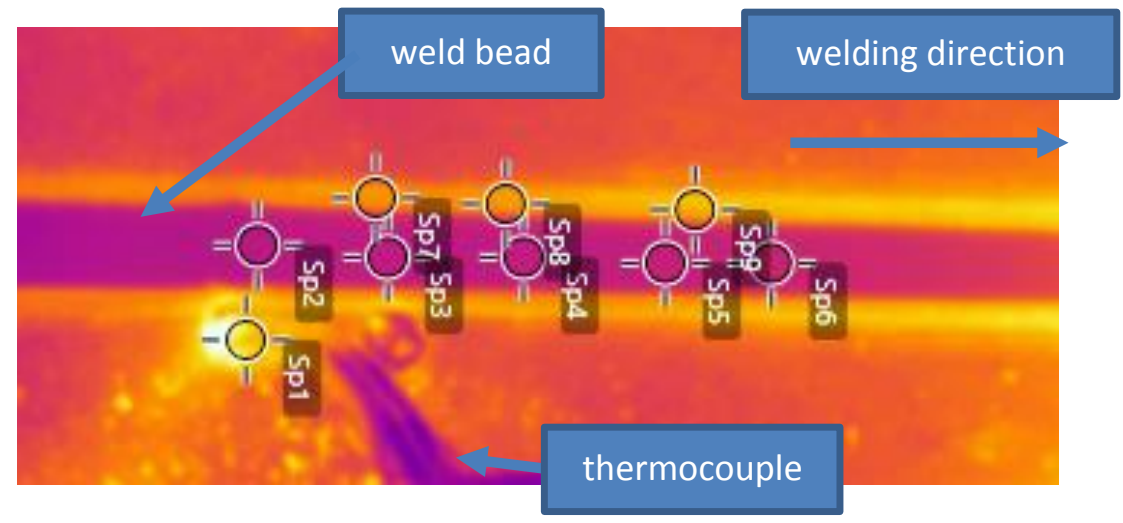

Figure 1. Temperature readings of the TIG welding by FLIR type thermal camera. 297 
In case of TIG welding with pure Ar shielding gas the measured average $\mathrm{dT}_{12 / 8}$ is $182^{\circ} \mathrm{C} / \mathrm{s}$, in case of $\mathrm{Ar}$ $+6 \% \mathrm{~N}_{2}$ the average $\mathrm{dT}_{12 / 8}$ is $165^{\circ} \mathrm{C} / \mathrm{s}$. The lower cooling rate is a result of the nitrogen addition to the arc plasma. The lower cooling rate also means that, more time is available for the solid-state ferrite-to-austenite transformation. The lower cooling rate and the nitrogen addition to the shielding gas are expected to give higher austenite fraction in the WM, compared to the pure argon TIG welded sample.

\subsection{Microstructure results after TIG welding}

The BMs initial average austenite fraction is $57.3 \%$. After TIG welding with pure argon shielding gas the austenite fraction in the WM decreased to average $29.9 \%$. The $6 \%$ nitrogen addition to the shielding gas resulted in higher, $59.5 \%$ austenite fraction in the WM. As it was expected, the lower $\mathrm{dT}_{12 / 8}$ cooling rate and the nitrogen addition to the shielding gas (as nitrogen is a very potent austenite former) resulted in higher austenite fraction in the WM. For possible chromium-nitride precipitation identification the electrochemical etching on the argon welded specimen was done, as described in the section 1.1.2. As the nitrogen solubility in the ferrites bcc lattice is significantly decreasing below $700{ }^{\circ} \mathrm{C}$ [37] only the argon TIG welded sample was evaluated with the chemical etching method. In Figure 2. the possible chromium-nitride precipitations are highlighted in the highly ferritic WM.

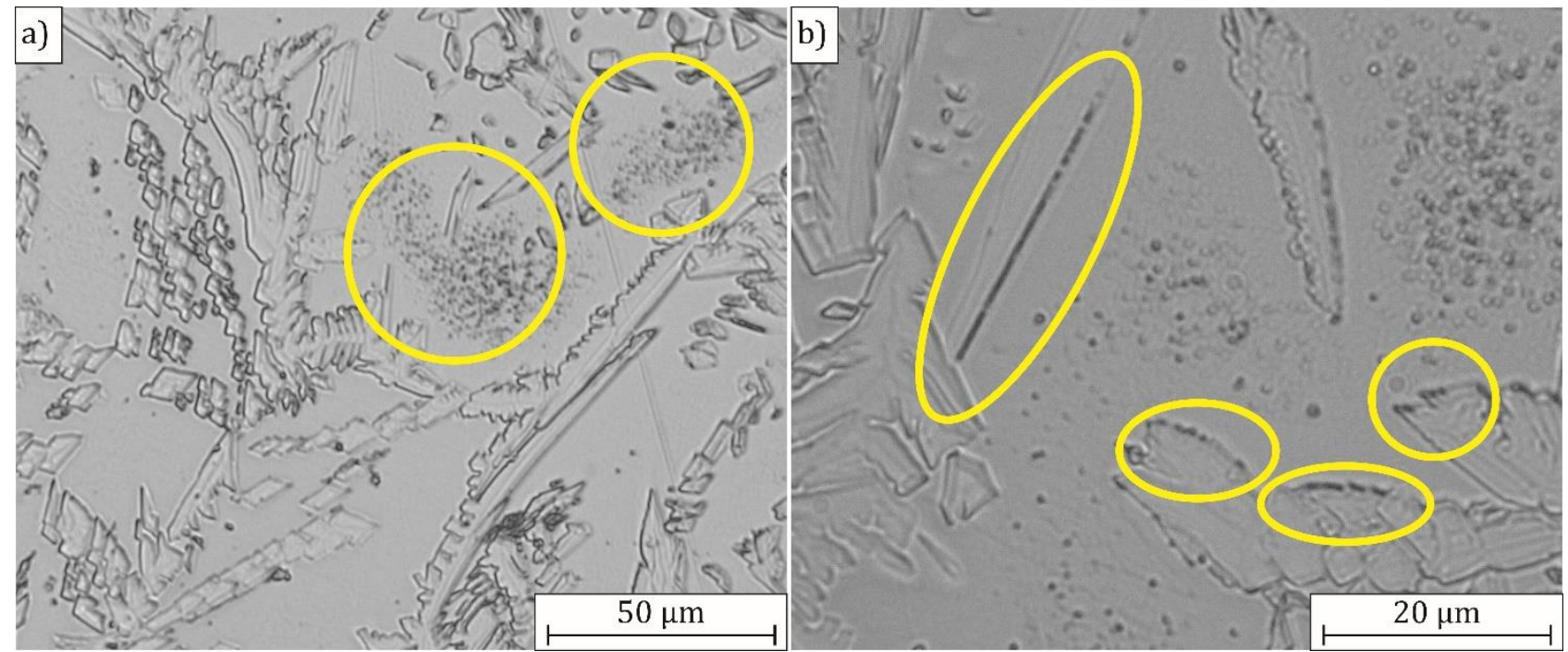

Figure 2. Chromium-nitride precipitations $\left(\mathrm{Cr}_{2} \mathrm{~N}\right)$ inside the ferrite grain a) and on the austenite-ferrite grain boundary b).

The chromium-nitride precipitation decreases the corrosion resistance [38-39] and the mechanical properties such as impact and fatigue strength [40-41]. On the other hand, as these chromium-nitride precipitations can dissolve in higher temperatures [42] they can act as secondary austenite formation nucleation sites [33]. During sub-sequent reheating, simulating multi-pass welds, the secondary austenite formation can highly increase the WMs austenite fraction. 


\subsection{Microstructure results after solid-state reheating}

The austenite fraction in the WM in case of argon welded sample increased from $29.9 \%$ to $48.7 \%$. In case of the argon $+6 \%$ nitrogen welded sample the austenite fraction in the WM increased from $59.5 \%$ to $64.5 \%$. In Figure 3. the microstructural images after the single pass reheating and the subsequent reheating can be seen in case of the argon welded sample. After the reheating the austenitic areas increased inside the ferrite grains. It means that, during the reheating the chromiumnitride precipitations dissolved and the high nitrogen content acted as a nucleation site for the secondary austenite formation. The higher amount of austenite fraction increase $(\sim 20 \%)$ in case of argon welded sample is a result of the high number of chromium-nitride precipitations. As the argon + $6 \%$ nitrogen welded sample originally had $59.5 \%$ austenite fraction, less chromium-nitride precipitated (because austenite has much higher solubility of nitrogen than ferrite [37]), thus the reheating caused only $5 \%$ increase in the austenite fraction.

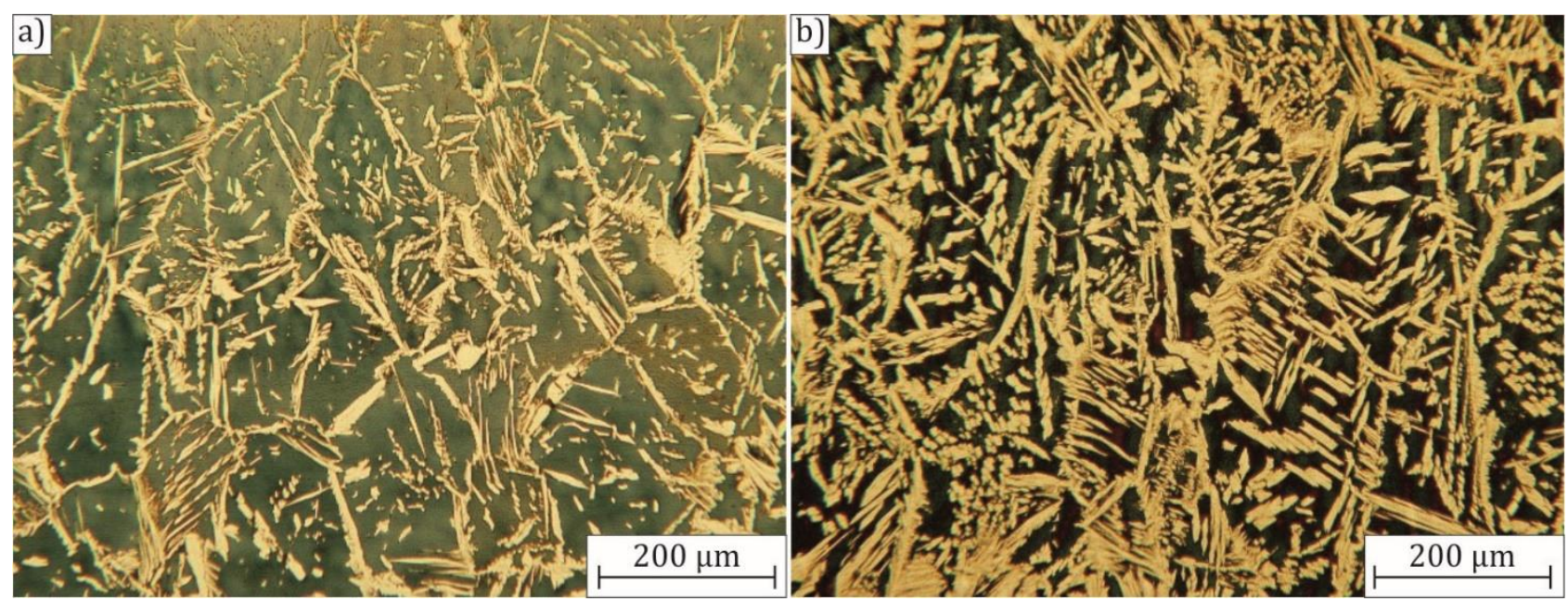

Figure 3. Weld metal microstructure of the argon welded sample, after TIG welding a) and after solid-state reheating $b$ )

\section{Conclusions}

From our current research the following conclusions can be drawn.

- The autogenously tungsten inert gas welding of $6 \mathrm{~mm}$ thick DSS 2205 duplex stainless steel sheets with $0.84 \mathrm{~kJ} / \mathrm{mm}$ arc energy and with argon $+6 \%$ nitrogen shielding gas resulted in lower $1200{ }^{\circ} \mathrm{C}$ to $800^{\circ} \mathrm{C}$ cooling rate, than the pure argon welded sample.

- After tungsten inert gas welding with pure argon shielding gas the austenite fraction in the weld metal decreased to average $29.9 \%$ (from the initial $57.3 \%$ ). The $6 \%$ nitrogen addition to the shielding gas resulted in higher, $59.5 \%$ austenite fraction in the weld metal.

- The electrochemical etching in $15 \%$ oxalic-acid solution, using $10 \mathrm{~V}$ direct potential for 10 seconds is suitable for chromium-nitride precipitation detection in DSS 2205.

- The sub-sequent tungsten inert gas solid-state reheating (simulating multi pass welding) caused increase in the austenite fraction in the weld metal in both cases. The argon welded samples 
austenite fraction of the argon welded and argon $+6 \%$ nitrogen welded samples increased by $+20 \%$ and $+5 \%$, respectively.

\section{Acknowledgement}

This paper has been supported by the János Bolyai Research Scholarship of the Hungarian Academy of Sciences grant number: Bo/00196/16/6 and by the National Research, Development and Innovation Office - NKFIH, OTKA PD 120865 (K. Májlinger). The research reported in this paper was supported by the BME-Nanonotechnology FIKP grant of EMMI (BME FIKP-NAT).

\section{References}

[1] L. Karlsson (2012) Welding Duplex Stainless Steels - a Review of Current Recommendations, Weld. World. 56 05/06, pp. 1-17.

[2] S. Baldo (2010) Innovative steels for structural and corrosion resistance applications, $\mathrm{PhD}$ thesis: Università degli Studi di Padova.

[3] P. Russo Spena - M. De Maddis - F. Lombardi - M. Rossini (2015) Investigation on resistance spot welding of TWIP steel sheets, steel Res. Int. 86 (12) pp. 1480-1489.

[4] A. Forgas Junior - J. Otubo - R. Magnabosco (2016) Ferrite Quantification Methodologies for Duplex Stainless Steel, J. Aerosp. Technol. Manag. 8 (3) pp. 357-362.

[5] A. Balogh - I. Török - M. Gáspár- D. Juhász (2012) Present state and future of advanced high strength steels, Prod. Process. Syst. 5 (1) pp. 79-90.

[6] H. Jaber - T. Kovács (2018) Dissimilar Resistance Spot Welding of Ferrite-Martensite Dual Phase Steel/Low Carbon Steel: Phase Transformations and Mechanical Properties, in Vehicle and Automotive Engineering 2. VAE 2018. Lecture Notes in Mechanical Engineering.

[7] B. Palotas - T. Pogonyi (2017) Results of resistance spot welding of dual phase steels, in Provisional agenda of the commission III intermediate meeting 2017 (III-1784-17).

[8] Y. Elarbi - B. Palotás (2007) Contributions of different factors to the improvement of the creep rupture strength of creep resistant martensitic steels, Period. Polytech. Mech. Eng. 51 (1) p. 33.

[9] G. Béres - Z. Weltsch (2018) Estimation of Strength Properties from Microhardness Results in Dual Phase Steels with Different Martensite Volume Fraction, Period. Polytech. Transp. Eng., no. 2015, pp. 1-7.

[10] R. N. Gunn (2017) Duplex stainless steels : microstructure, properties and applications. Abington Publishing.

[11] I. Mészáros - B. Bögre (2018) Microstructural and magnetic investigations of duplex steel, IOP Conf. Ser. Mater. Sci. Eng., vol. 426, p. 012034.

[12] A. Vinoth Jebaraj - L. Ajaykumar - C. R. Deepak - K. V. V. Aditya (2017) Weldability, machinability and surfacing of commercial duplex stainless steel AISI2205 for marine applications - A recent review, J. Adv. Res. 8 (3) pp. 183-199.

[13] E. M. Westin - B. Brolund - S. Hertzman (2008) Weldability Aspects of a Newly Developed Duplex Stainless Steel LDX 2101, Steel Res. Int. 79 (6) pp. 473-481.

[14] T. Berecz - É. Fazakas - I. Mészáros - I. Sajó (2015) Decomposition kinetics of ferrite in isothermally aged SAF2507 type duplex stainless steel, J. Mater. Eng. Perform. 24, pp. 4777-4788. 
[15] E. R. Fábián - J. Dobránszky - J. Csizmazia - R. Ott (2017) Effect of laser beam welding on the microstructure of duplex stainless steels, Mater. Sci. Forum, vol. 885, pp. 245-250.

[16] V. Quiroz - A. Gumenyuk - M. Rethmeier (2012) Laser Beam Weldability of High-Manganese Austenitic and Duplex Stainless Steel Sheets, Weld. World. 56 (1-2) pp. 9-20.

[17] A. Vinoth Jebaraj - L. Ajaykumar (2013) Influence of Microstructural Changes on Impact Toughness of Weldment and Base Metal of Duplex Stainless Steel AISI 2205 for Low Temperature Applications, Procedia Eng. vol. 64, pp. 456-466.

[18] H. Y. Liou - R. I. Hsieh - W. T. Tsai (2002)Microstructure and stress corrosion cracking in simulated heat-affected zones of duplex stainless steels, Corros. Sci. 44 (12) pp. 2841-2856.

[19] F. Zanotto - V. Grassi - A. Balbo - C. Monticelli - F. Zucchi (2014) Stress corrosion cracking of LDX 2101 duplex stainless steel in chloride solutions in the presence of thiosulphate, Corros. Sci., vol. 80, pp. 205-212.

[20] J. Olsson - M. Snis (2007) Duplex - A new generation of stainless steels for desalination plants, Desalination. 205 (1-3) pp. 104-113.

[21] P. Boillot - J. Peultier (2014) Use of stainless steels in the industry: recent and future developments, Procedia Eng. vol. 83, pp. 309-321.

[22] A. Igual Muñoz - J. García Antón - J. L. Guiñón - V. Pérez Herranz (2005) Effect of nitrogen in Argon as a shielding gas on tungsten inert gas welds of duplex stainless steels, Corrosion. 61. (7) pp. 693-705.

[23] G. da Fonseca - L. Barbosa - E. Ferreira - C. Xavier - J. de Castro (2017) Microstructural, Mechanical, and Electrochemical Analysis of Duplex and Superduplex Stainless Steels Welded with the Autogenous TIG Process Using Different Heat Input, Metals (Basel). 7 (12) p. 538.

[24] E. Westin (2010) Microstructure and properties of welds in the lean duplex stainless steel LDX 2101. PhD thesis.

[25] K. Migiakis - G. D. Papadimitriou (2009) Effect of nitrogen and nickel on the microstructure and mechanical properties of plasma welded UNS S32760 super-duplex stainless steels, J. Mater. Sci., 44 (23) pp. 6372-6383.

[26] E. M. Westin - M. M. Johansson - R. F. A. Pettersson (2013) Effect of nitrogen-containing shielding and backing gas on the pitting corrosion resistance of welded lean duplex stainless steel LDX 2101 ${ }^{\circledR}$ (EN 1.4162, UNS S32101), Weld. World. 57 (4) pp. 467-476.

[27] M. A. A. Valiente Bermejo et al. (2015) Effect of shielding gas on welding performance and properties of duplex and superduplex stainless steel welds, Weld. World. 59 (2) pp. 239-249,

[28] V. A. Hosseini (2016) Influence of multiple welding cycles on microstructure and corrosion resistance of a super duplex stainless steel, $\mathrm{PhD}$ thesis, University West.

[29] Z. Zhang - H. Jing - L. Xu - Y. Han - L. Zhao (2016) Investigation on microstructure evolution and properties of duplex stainless steel joint multi-pass welded by using different methods, Mater. Des., vol. 109. pp. 670-685.

[30] V. A. Hosseini - M. A. Valiente Bermejo - J. Gårdstam - K. Hurtig - L. Karlsson (2016) Influence of multiple thermal cycles on microstructure of heat-affected zone in TIG-welded super duplex stainless steel, Weld. World. 60 (2) pp. 233-245.

[31] J. Ramírez-Salgado - M. A. Domínguez-Aguilar - B. Castro-Domínguez - P. Hernández-Hernández - R. C. Newman (2013) Detection of secondary phases in duplex stainless steel by magnetic force microscopy and scanning Kelvin probe force microscopy, Mater. Charact., vol. 86, pp. 250-262. 
[32] A. J. Ramirez - J. C. Lippold - S. D. Brandi (2003) The relationship between chromium nitride and secondary austenite precipitation in duplex stainless steels, Metall. Mater. Trans. A. 34 (8) pp. 1575-1597.

[33] C. M. Garzón - A. J. Ramirez (2006) Growth kinetics of secondary austenite in the welding microstructure of a UNS S32304 duplex stainless steel, Acta Mater. 54 (12) pp. 3321-3331.

[34] B. Varbai - T. Pickle - K. Májlinger (2018)Development and Comparison of Quantitative Phase Analysis for Duplex Stainless Steel Weld, Period. Polytech. Mech. Eng. 62 (3) pp. 247-253.

[35] S. Geng - J. Sun - L. Guo - H. Wang (2015) Evolution of microstructure and corrosion behavior in 2205 duplex stainless steel GTA-welding joint, J. Manuf. Process., vol. 19, pp. 32-37.

[36] J. Verma - R. V. Taiwade (2017) Effect of welding processes and conditions on the microstructure, mechanical properties and corrosion resistance of duplex stainless steel weldments-A review, J. Manuf. Process., vol. 25, pp. 134-152.

[37] J. C. Lippold and D. J. Kotecki (2005)Welding metallurgy and weldability of stainless steels. John Wiley, p. 357.

[38] J. C. de Lacerda - L. C. Cândido - L. B. Godefroid (2015) Corrosion behavior of UNS S31803 steel with changes in the volume fraction of ferrite and the presence of chromium nitride, Mater. Sci. Eng. A, vol. 648, pp. 428-435.

[39] K. Sun - M. Zeng - Y. Shi - Y. Hu - X. Shen (2018) Microstructure and corrosion behavior of S32101 stainless steel underwater dry and wet welded joints, J. Mater. Process. Technol., vol. 256, no. February, pp. 190-201.

[40] S. Hereñú - M. G. Moscato - I. Alvarez - A. F. Armas (2014) The Influence of Chromium Nitrides Precipitation on the Fatigue Behavior of Duplex Stainless Steels, Procedia Eng., vol. 74, pp. 179182.

[41] I. Zucato - M. C. Moreira - I. F. Machado - S. M. Giampietri (2002) Microstructural Characterization and the Effect of Phase Transformations on Toughness of the UNS S31803 Duplex Stainless Steel Aged Treated at $850^{\circ} \mathrm{C}$, Mater. Res. 5 (3) pp. 385-389.

[42] S. M. Howard, Ellingham Diagrams. [Online]. Available: http://showard.sdsmt.edu/MET320/Handouts/EllinghamDiagrams/Ellingham_v22_Macro.pdf. (downloaded: 14-11-2018) 